Sachin Rai, Navin Chaurasiya, Pramod K. Yadawa

\title{
Elastic, Mechanical and Thermophysical properties of Single-Phase Quaternary ScTiZrHf High-Entropy Alloy
}

\author{
Department of Physics, Prof. Rajendra Singh (RajjuBhaiya) Institute of Physical Sciences for Study and Research, \\ V B.S. Purvanchal University, Jaunpur, India, pkyadawa@gmail.com
}

\begin{abstract}
Consequent to the interaction potential model, the high-order elastic constants at high entropy alloys in singlephase quaternary ScTiZrHf have been calculated at room temperature. Elastic constants of second order (SOECs) helps to determine other ultrasonic parameters. With the help of SOECs other elastic moduli, bulk modulus, shear modulus, Young's modulus, Pugh's ratio, elastic stiffness constants and Poisson's ratio are estimated at room temperature for elastic and mechanical characterization. The other ultrasonic parameters are calculated at room temperature for elastic and mechanical characterization. The temperature variation of ultrasonic velocities along the crystal's z-axis is evaluated using SOECs. The temperature variation of the average debye velocity and the thermal relaxation time $(\tau)$ are also estimated along this orientation axis. The ultrasonic properties correlated with elastic, thermal and mechanical properties which is temperature dependent is also discussed. The ultrasonic attenuation due to phonon - phonon ( $\mathrm{p}-\mathrm{p}$ ) interactions is also calculated at different temperatures. In the study of ultrasonic attenuation such as a function of temperature, thermal conductivity appears to be main contributor and $p$ - $p$ interactions are the responsible reason of attenuation and found that the mechanical properties of the high entropy alloy ScTiZrHf are superior at room temperature.
\end{abstract}

Key words: high entropy alloy, ultrasonic properties, thermal conductivity, elastic properties.

Received 28 Juiy 2021; Accepted 10 October 2021.

\section{Introduction}

High-entropy alloys (HEAs) have involved considerable attention as they have first proposed in the physical metallurgy community [1]. HEAs is distinct as an alloy involving of at least five principal elements with equivalent equilateral ratios, which could favour the construction of homogeneous solid solution stages rather than intermetallic compounds [2]. Indubitable, the presence of HEAs accelerates the development of metallurgical materials and opens a new path for the discovery of new alloys without understanding the properties [3, 4]. Several interesting properties were suggested for HEAs, acting asexcellent high strength [5, 6], high fracture toughness at low temperatures, high hardness and thermal stability [7]. The opportunity of creation of HEAs with rare-earth metal, first proposed via Zhang et al. [8], since rare earth materials have very similar atomic sizes, the same crystal structures and large or fully related solubility. This confirmed CoFeReRu alloys could form solutions as a single hexagonal solid and the equivalent hexagonal HEAs can be formed between $\mathrm{Y}$, $\mathrm{Sc}, \mathrm{Tb}, \mathrm{Gd}, \mathrm{Di}, \mathrm{Tm}, \mathrm{Ho}, \mathrm{Tm}, \mathrm{Er}$, and Lu. Establishment of rare earth element HEAs was revealed in DyGdHoTbY by Feuerbacher et al. [9], DyGdLuTbTm and DyGdLuTbY by Takeuchi et al. [10]. High-entropy alloys have demonstrated the ability to have superior properties in many cases. A basic understanding of the mechanism of phase stability of HEAs is still a subject of active research [11]. HEAs were found own many attractive properties, like soft magnetism [12], larger hardness [13], high strength [14], excellent corrosion resistance, better thermal stability and high wear resistance etc. [15]. The certain outstanding properties of HEAs were contributed to a growing interest in research and improvement in a new exciting field [16]. Y. L. Chen and his co-workers [17] designed equimolar BeCoMgTiZn and BeCoMgTi alloys, whose component elements are all stable in 
hexagonal structure by mechanical alloying, then contain only amorphous phases rather than solid solution phases. The construction of a single-phase hop structure in rareearth HEAs systems was first reported in HoDyYGdTb system and later confirmed in DyGdLuTbTm, DyGdLuTbY, GdHoLaTbTm, TbDyHoErY, DyGdHoLaTbY, DyErGdHo- LuScTbY and others. The structure for all discovered rare earth elements was determined only in the as-cast state. Some of these singlephase arrangements may be those that are unstable on mechanical deformation, thermal processing and other factors [18-22]. Ultrasonic attenuation (UA) is the main physical parameters to describe a compound, which appreciates the specific relationship between the anisotropic behaviour of the adjacent atomic planes and affinity and the structural motion, some physical quantities such as specific heat, thermal energy density and thermal conductivity is well associated with higherorder elastic constants[23, 24].

In our present evaluation, we predict the ultrasonic properties of hexagonal hexagonal single-phase quaternary ScTiZrHf high entropy alloys. For that, we have evaluated the UA coefficient, acoustic coupling constant, second order elastic constants, third order elastic constants (TOECs), ultrasonic velocities and thermal relaxation time for this high entropy alloy. The related mechanical properties, such as Bulk modulus (B), Young's modulus (Y), Shear modulus (G), Pugh's ratio (B / G) and Poisson's ratio $(\sigma)$ for the high entropy alloy, are also evaluated. Investigation of these properties will offer a database to know the mechanical behavior of ScTiZrHf high entropy alloy and it will show a key role in the design of industrialized apparatus with needed physical properties under ambient working conditions.

\section{Theory}

The interaction potential model techniques are wellconventional principles for deduction for high-order elastic constants of hexagonal structured material. According present effort, the Lenard Jones interaction potential model method was using for the valuation for second and third order elastic constants.

A common description of $n^{\text {th }}$ order elastic constant is the partial derivatives of thermodynamic potential of the medium constrained finite deformation as well as mathematically conveyed by subsequent expression as $[25,26]$ :

$$
C_{i j k l m n \ldots}=\frac{\partial^{n} F}{\partial \eta_{i j} \partial \eta_{k l} \partial \eta_{m n} \cdots}
$$

Whenever, $F$ isdenoted free energy density and $\eta_{i j}$ is denote Lagrangian strain component tensor. $F$ may be extended in relations of strain $\eta$ by Taylor series expansion as:

$$
F=\sum_{n=0}^{\infty} F_{n}=\sum_{n=0}^{\infty} \frac{1}{n !}\left(\frac{\partial^{n} F}{\partial \eta_{i j} \partial \eta_{k l} \partial \eta_{m n} \cdots}\right) \eta_{i j} \eta_{k l} \eta_{m n}
$$

Thereby, the free energy density is written such as:

$$
F_{2}+F_{3}=\frac{1}{2 !} C_{i j k l} \eta_{i j} \eta_{k l}+\frac{1}{3 !} C_{i j k l m n} \eta_{i j} \eta_{k l} \eta_{\mathrm{mn}}
$$

In order that hexagonal compounds the basis vectors are $a_{1}=a\left(\frac{\sqrt{3}}{2}, \frac{1}{2}, 0\right), \quad a_{2}=a(0,1,0) \quad$ and $\quad a_{3}=$ $a(0,0, c)$ in cartesian coordinates axis. Where $a$ and $c$ are the unit cell lattice parameters. The unit cell of HCP compound contains of two nonequivalent atoms: 6- atoms in basal plane and 3-3 atoms upper and lower the basal plane. The consequently, both first and second neighborhood contains of 6- atoms. Were $r_{1}=$ $a(0,0,0)$ and $r_{2}=\left(\frac{a}{2 \sqrt{3}}, \frac{a}{2}, \frac{c}{2}\right)$ are the location vectors of those two kinds of atoms.

The potential energy per unit cell up to second adjacent neighbour is scripted following:

$$
U_{2}+U_{3}=\Sigma_{I=1}^{6} U\left(r_{I}\right)+\Sigma_{J=1}^{6} U\left(r_{J}\right)
$$

anywhere, $I$ refer to atoms in the basal plane and $J$ refers to atoms above and below the basal plane. Whenever the crystal is deformable uniformly then interatomic vectors in non-deformed state $(r)$ and deformable state $\left(r^{\prime}\right)$ are associated as:

$$
\left(r^{\prime}\right)^{2}-(r)^{2}=2 \varepsilon_{i} \varepsilon_{j} \eta_{i j}=2 \Theta
$$

Whenever, $\varepsilon_{i}$ and $\varepsilon_{j}$ are the Cartesian component of vector $r$. The energy density $U$ may be describingbased on $\Theta$ as $[27,28]$ :

$$
U_{n}=\left(2 V_{c}\right)^{-1} \Sigma \frac{1}{n !} \Theta^{n} D^{n} \varphi(r)
$$

Above equations (4) and (6b), the energy density $U$ involving cubic terms can be written as:

$$
\begin{aligned}
& U_{2}+U_{3}=\left(2 V_{c}\right)^{-1}\left[\sum_{I=1}^{6} \frac{1}{2 !} \Theta_{I}^{2} D^{2} \varphi\left(r_{I}\right)+\sum_{J=1}^{6} \frac{1}{2 !} \Theta_{J}^{2} D^{2} \varphi\left(r_{J}\right)\right] \\
& +\left(2 V_{c}\right)^{-1}\left[\sum_{I=1}^{6} \frac{1}{3 !} \Theta_{I}^{3} D^{3} \varphi\left(r_{I}\right)+\sum_{J=1}^{6} \frac{1}{3 !} \Theta_{J}^{3} D^{3} \varphi\left(r_{J}\right)\right]
\end{aligned}
$$

Where, $V_{c}=\left[3^{1 / 2} / 2\right] a^{2} c$ signifying the volume of the elementary cell, $D=R^{-1} d / d R$ and $\varphi(r)$ is the interaction potential. The energy density is examined to be function of Lennard Jones potential and specified as:

$$
\varphi(r)=-\frac{a_{0}}{r^{m}}+\frac{b_{0}}{r^{n}}
$$


where, $a_{0}, b_{0}$ are constants; $m, n$ are the integers and $r$ is the distance between atoms. Establish the interaction potential model leads to computed six SOECs and ten
TOECs of the hexagonal compound and formulations of elastic constants are given as following expressions [25, $26]$.

$$
\left.\begin{array}{l}
C_{12}=5.918 \mathrm{p}^{4} C^{\prime} \\
C_{33}=3.464 \mathrm{p}^{8} C^{\prime} \\
C_{66}=9.851 \mathrm{p}^{4} C^{\prime}
\end{array}\right\}
$$

$$
\left.\begin{array}{rlrl}
C_{111} & =126.9 p^{2} B+8.853 p^{4} C^{\prime} & & C_{112}=19.168 p^{2} B-1.61 p^{4} C^{\prime} \\
C_{113} & =1.924 p^{4} B+1.155 p^{6} C^{\prime} & & C_{123}=1.617 p^{4} B-1.155 p^{6} C^{\prime} \\
C_{133} & =3.695 p^{6} B & C_{155}=1.539 p^{4} B \\
C_{144} & =2.309 p^{4} B & C_{344} & =3.464 p^{6} B \\
C_{222} & =101.039 p^{2} B+9.007 p^{4} C^{\prime} & C_{333} & =5.196 p^{8} B
\end{array}\right\}
$$

where $\mathrm{p}=\mathrm{c} / \mathrm{a}$ : axial ratio; $C^{\prime}=\chi \mathrm{a} / \mathrm{p}^{5} ; B=\psi \mathrm{a}^{3} / p^{3} ; \chi=(1 / 8)\left[\left\{n b_{0}(n-m)\right\} /\left\{\mathrm{a}^{n+4}\right\}\right] \psi=-\chi /\left\{6 \mathrm{a}^{2}(m+n+6)\right\}$; $\mathrm{m}, \mathrm{n}=$ integer quantity; $\mathrm{b}_{0}=$ Lennard- Jones parameter.

The bulk modulus and shear modulus were calculated using Voigt and Reuss' methodologies [27, 28]. The calculations of unvarying stress and unvarying strain were used in the Voigt and Reuss' methodologies, correspondingly. Furthermore, From Hill's methods, the average values of both methodologies were used toward compute ensuing values of B and G [29]. Young's modulus and Poisson's ratio are considered using values of bulk modulus and shear modulus respectively [30, 31]. The following expressions were used for the evaluation of $\mathrm{Y}, \mathrm{B}, \mathrm{G}$ and $\sigma$ [32].

$$
\begin{aligned}
& \left.M=C_{11}+C_{12}+2 C_{33}-4 C_{13} ; \mathrm{C}^{2}=\left(C_{11}+C_{12}\right) C_{33}-4 C_{13}+C^{2}{ }_{13} ;\right) \\
& B_{R}=\frac{C^{2}}{M} ; \mathrm{B}_{V}=\frac{2\left(C_{11}+C_{12}\right)+4 C_{13}+C_{33}}{9} \text {; } \\
& G_{V}=\frac{M+12\left(C_{44}+C_{66}\right)}{30} ; \mathrm{G}_{R}=\frac{5 C^{2} C_{44} C_{66}}{2\left[3 B_{V} C_{44} C_{66}+C^{2}\left(C_{44}+C_{66}\right)\right]} ; \\
& Y=\frac{9 G B}{G+3 B} ; \quad \mathrm{B}=\frac{B_{V}+B_{R}}{2} ; \quad \mathrm{G}=\frac{G_{V}+G_{R}}{2} ; \sigma=\frac{3 \mathrm{~B}-2 \mathrm{G}}{2(3 \mathrm{~B}+G)}
\end{aligned}
$$

The anisotropic and mechanical properties of nanostructured materials are well correlated with ultrasonic velocity due to the velocity of ultrasonic wave are mainly depending upon the SOECs and density. As a function of mode of vibration, those are three types of ultrasonic velocities in hexagonal nanostructured compound. First longitudinal $V_{L}$ and second shear $\left(V_{S 1}, V_{S 2}\right)$ waves velocities. Ultrasonic velocities on the basis of angle between direction of propagation and z- axis for hexagonal nanostructured compound are given by subsequent set of equations:

$$
\left.\begin{array}{l}
V_{L}^{2}=\left\{C_{33} \cos ^{2} \theta+C_{11} \sin ^{2} \theta+C_{44}+\left\{\left[C_{11} \sin ^{2} \theta-C_{33} \cos ^{2} \theta+C_{44}\left(\cos ^{2} \theta-\sin ^{2} \theta\right)\right]^{2}\right.\right. \\
\left.\left.+4 \cos ^{2} \theta \sin ^{2} \theta\left(C_{13}+C_{44}\right)^{2}\right\}^{1 / 2}\right\} / 2 \rho \\
V_{S 1}^{2}=\left\{C_{33} \cos ^{2} \theta+C_{11} \sin ^{2} \theta+C_{44}-\left\{\left[C_{11} \sin ^{2} \theta-C_{33} \cos ^{2} \theta+C_{44}\left(\cos ^{2} \theta-\sin ^{2} \theta\right)\right]^{2}\right\}\right. \\
\left.\left.+4 \cos ^{2} \theta \sin ^{2} \theta\left(C_{13}+C_{44}\right)^{2}\right\}^{1 / 2}\right\} / 2 \rho \\
V_{S 2}^{2}=\left\{C_{44} \cos ^{2} \theta+C_{66} \sin ^{2} \theta\right\} / \rho
\end{array}\right\}
$$

where, $V_{L}, V_{S 1}$, and $V_{S 2}$ are the longitudinal, quasi-shear and shear wave velocities. Also, $\rho$ is the density of compound and $\theta$ is angle with the unique axis of the crystal. For hexagonal nanostructured crystal the Debye average velocity is specified by the equation as [33, 34]:

$$
V_{D}=\left[\frac{1}{3}\left(\frac{1}{V_{L}^{3}}+\frac{1}{V_{S 1}^{3}}+\frac{1}{V_{32}^{3}}\right)\right]^{-1 / 3} \text {. }
$$

At the low temperatures $(<100 \mathrm{~K})$, the electronphonon interaction is dominating processes for attenuation of ultrasonic wave. At this temperature, regime the mean free path of electron is alike as the mean free path of acoustical phonons. Accordingly, a high probability coupling arises between free electrons and acoustic phonons [25]. The mathematical formulation of ultrasonic attenuation for longitudinal $(\alpha)_{\text {Long }}$ and shear waves $(\alpha)_{\text {Shear }}$ induced by the energy loss due to electron-phonon interaction is given by:

$$
\begin{gathered}
\alpha_{\text {long }}=\frac{2 \pi^{2} f^{2}}{\rho V_{l}^{3}}\left(\frac{4}{3} \eta_{e}+\chi\right), \\
\alpha_{\text {shear }}=\frac{2 \pi^{2} f^{2}}{\rho V_{S}^{3}} \eta_{e},
\end{gathered}
$$

where ' $\rho$ ' is the density of nanostructured compound, ' $f$ ' is the frequency of the ultrasonic wave, ' $\eta_{\mathrm{e}}$ ' is the electron viscosity and ' $\chi$ ' is the compressional viscosity (which is zero in present case), $\mathrm{V}_{\mathrm{L}}$ and $\mathrm{V}_{\mathrm{S}}$ are the acoustic wave velocities for longitudinal and shear waves respectively and are given as: 


$$
V_{L}=\sqrt{\frac{C_{33}}{\rho}} \text { and } V_{S}=\sqrt{\frac{C_{44}}{\rho}}
$$
by:

The viscosity of the electron gas $\left(\eta_{e}\right)[21,22]$ is given

$$
\eta_{e}=\frac{9 \times 10^{11} h^{2}\left(3 \pi^{2} N\right)^{2 / 3}}{5 e^{2} R}
$$

Wherever ' $N$ ' represents the number of molecules per unit volume, and ' $R$ ' is the resistivity.

At higher temperature, $p-p$ interaction (Akhieser's type loss) and thermoelastic loss are the two prevailing processes, whichever are considerable for attenuation of ultrasonic wave. The attenuation by virtue of Akhieser's loss is specified by the subsequent equation:

$$
\left(\alpha / f^{2}\right)_{A k h}=\frac{4 \pi^{2} \tau E_{0}(D / 3)}{2 \rho V^{3}}
$$

Here, $f$ represents the frequency of the ultrasonic wave; $E_{0}$ is the thermal energy density. The measure of transforming of acoustical energy into thermal energy is recognized as acoustical coupling constants, signified by $D$, and is specified by subsequent expression:

$$
D=3\left(3 E_{0}<\left(\gamma_{i}^{j}\right)^{2}>-<\gamma_{i}^{j}>^{2} C_{V} T\right) / E_{0},
$$

where $C_{V}$ is the specific heat per unit volume of the material, $T$ is the temperature and $\gamma_{i}^{j}$ is the Grüneisen number; $i$ and $j$ are the mode and direction of the propagation. While the ultrasonic waves transmit through the material, equilibrium of lattice phonon distribution gets disturbed. The time takes for re-establishment of equilibrium of the thermal phonons is named as thermal relaxation time, signified by $\tau$, and is specified by subsequent expression:

$$
\tau=\tau_{S}=\tau_{L} / 2=\frac{3 k}{C_{V} V_{D}^{2}}
$$

Wherever the thermal relaxation time for the longitudinal wave and shear wave are signified by $\tau_{L}$ and $\tau_{S}$ correspondingly, ' $k$ ' is the thermal conductivity of the nanostructured compound. The thermoelastic loss $(\alpha /$ $\left.f^{2}\right)_{T h}$ is considered by the subsequent equation:

$$
\left(\alpha / f^{2}\right)_{T h}=4 \pi^{2}<\gamma_{i}^{j}>^{2} \frac{k T}{2 \rho V_{L}^{5}}
$$

The total attenuation is specified by the subsequent equation as:

$$
\left(\alpha / f^{2}\right)_{\text {Total }}=\left(\alpha / f^{2}\right)_{T h}+\left(\alpha / f^{2}\right)_{L}+\left(\alpha / f^{2}\right)_{S}
$$

Wherever $\left(\alpha / f^{2}\right)_{T h}$ is the thermoelastic loss, $(\alpha /$ $\left.f^{2}\right)_{L}$ and $\left(\alpha / f^{2}\right)_{S}$ are the ultrasonic attenuation coefficient for the longitudinal wave and shear wave correspondingly.

\section{Results and discussion}

\subsection{Higher order elastic constants}

In present analysis, we have calculated the elastic constants (six SOECs and ten TOECs) using interaction potential model. The unit cell parameters 'a' (basal plane parameter) and 'p' (axial ratio) for ScTiZrHf are $3.185 \AA$ and 1.573 respectively [35]. The chosen value of $m$ and $n$ for high entropy alloy are 6 and 7 . The value of $b_{0}$ is $1.695 \times 10^{-64} \mathrm{erg} \mathrm{cm}^{7}$ for ScTiZrHf high entropy alloy. The evaluated values of SOECs, TOECs and bulk modulus for this high entropy alloy at room temperature is shown in Table 1 .

ScTiZrHf high entropy alloys had the highest elastic constant values, which are the significant for the material, since they are associated with the hardness parameter. SOECs are used to determine the UA and associated parameters [35, 36]. Higher order elastic constant values found for high entropy alloys are indicative of their better mechanical properties over other entropy alloys of the similar group. Obviously, for a stable hexagonal type structure, the five independent SOECs ( $\mathrm{Cij}$, namely $\mathrm{C}_{11}$, $\mathrm{C}_{12}, \mathrm{C}_{13}, \mathrm{C}_{33}, \mathrm{C}_{44}$ ) should satisfy the well-known BornHuang's stability conditions $[29,30]$.i.e. $\mathrm{C}_{11}-\left|\mathrm{C}_{12}\right|>0$, $\left(\mathrm{C}_{11}+\mathrm{C}_{12}\right) \mathrm{C}_{33}-2 \mathrm{C}^{2}{ }_{13}>0, \mathrm{C}_{11}>0$ and $\mathrm{C}_{44}>0$. In Table 1, it is evident that the elastic constant values of all are positive and satisfied the Born-Huang's mechanical stability limits and therefore this HEAs are mechanically stable. The Debye temperature for ScTiZrHf high entropy alloy is evaluated to be $247.7 \mathrm{~K}$, while the value reported for the same is $247 \mathrm{~K}$ [35]. Therefore, there is good agreement between the presented and reported values. Debye temperature is correlated with elastic constants of the material. Thus, our theoretical method is well justified for

\begin{tabular}{|c|c|c|c|c|c|c|c|c|c|c|}
\hline HE Alloy & $\mathrm{C}_{11}$ & $\mathrm{C}_{12}$ & $\mathrm{C}_{13}$ & $\mathrm{C}_{33}$ & $\mathrm{C}_{44}$ & $\mathrm{C}_{66}$ & B & & & \\
\hline ScTiZrHf & 212 & 52 & 42 & 186 & 50 & 83 & 103 & & & \\
\hline HE Alloy & $\mathrm{C}_{111}$ & $\mathrm{C}_{112}$ & $\mathrm{C}_{113}$ & $\mathrm{C}_{123}$ & $\mathrm{C}_{133}$ & $\mathrm{C}_{344}$ & $\mathrm{C}_{144}$ & $\mathrm{C}_{155}$ & $\mathrm{C}_{222}$ & $\mathrm{C}_{333}$ \\
\hline ScTiZrHf & $\begin{array}{c}- \\
3449\end{array}$ & -547 & -107 & -136 & -629 & $\begin{array}{c}- \\
589\end{array}$ & -159 & -106 & -2729 & -2188 \\
\hline
\end{tabular}
calculation of SOECs of hexagonal HEAs at room temperature. We present the calculated value of TOECs in Table 1. The negative values of third order elastic constants indicate a negative strain in the solid. However,

Table 1

SOECs, TOECs and bulk modulus (inGPa) at room temperature. 
Table 2

Voigt-Reuss' constants $\left(\mathrm{M}\right.$ and $\mathrm{C}^{2)}$, Bulk modulus $\left(\mathrm{x} 10^{10} \mathrm{Nm}^{-2}\right)$, Shear Modulus $\left(\times 10^{10} \mathrm{Nm}^{-2}\right)$, Young's Modulus $\left(\mathrm{x} 10^{10} \mathrm{Nm}^{-2}\right)$, Poisson's Ratio, Pugh's Ratio for ScTiZrHf high entropy alloy

\begin{tabular}{|c|c|c|c|c|c|c|c|c|c|c|}
\hline HE Alloy & $\mathrm{M}$ & $\mathrm{C}^{2}$ & $\mathrm{~B}_{\mathrm{r}}$ & $\mathrm{B}_{\mathrm{v}}$ & $\mathrm{G}_{\mathrm{r}}$ & $\mathrm{G}_{\mathrm{v}}$ & $\mathrm{Y}$ & $\mathrm{B} / \mathrm{G}$ & $\mathrm{G} / \mathrm{B}$ & $\sigma$ \\
\hline ScTiZrHf & 468 & 50623 & 108 & 98 & 66 & 69 & 166 & 1.52 & 0.66 & 0.231 \\
\hline
\end{tabular}

Table 3

\begin{tabular}{|c|c|c|c|c|c|c|}
\hline$\rho:\left(\times 10^{3} \mathrm{~kg} \mathrm{~m}^{-3}\right), \mathrm{C}_{\mathrm{V}}:\left(\mathrm{x} 10^{5} \mathrm{Jm}^{-3} \mathrm{~K}^{-1}\right), \mathrm{E}_{0}:\left(\mathrm{x} 10^{8} \mathrm{Jm}^{-3}\right), \mathrm{k}:\left(\mathrm{x} 10^{4} \mathrm{Wm}^{-1} \mathrm{~K}^{-1}\right)$ and $\left(\mathrm{D}_{\mathrm{L},} \mathrm{D}_{\mathrm{S}}\right)$ of ScTiZrHf HE alloy \\
\hline Temp [K] & $\rho$ & $\mathrm{C}_{\mathrm{V}}$ & $\mathrm{E}_{0}$ & $\mathrm{k}$ & $\mathrm{D}_{\mathrm{L}}$ & $D_{S}$ \\
\hline 300 & 8.2 & 5.470 & 1.229 & 6.875 & 56.458 & 1.615 \\
350 & 8.18 & 5.510 & 1.492 & 7.562 & 56.510 & 1.615 \\
400 & 8.16 & 5.519 & 1.771 & 8.187 & 56.575 & 1.615 \\
450 & 8.14 & 5.525 & 2.044 & 8.687 & 56.808 & 1.615 \\
500 & 8.12 & 5.530 & 2.314 & 9.250 & 56.648 & 1.615 \\
550 & 8.1 & 5.535 & 2.586 & 9.687 & 56.675 & 1.615 \\
600 & 8.08 & 5.531 & 2.852 & 10.125 & 56.692 & 1.615 \\
650 & 8.06 & 5.527 & 3.125 & 10.500 & 56.712 & 1.615 \\
700 & 8.04 & 5.522 & 3.389 & 10.812 & 56.724 & 1.615 \\
\hline
\end{tabular}

third order elastic constants are not compared due to lack of data in the literature but the negative third order elastic constants are found in previous papers for hexagonal structure materials. Therefore, the theory applied for valuation of higher order elastic constants is justified [3639]. Hence the applied theory for the valuation of higher order elastic constants is justified. Bulk modulus, shear modulus, Young's modulus, Pugh's ratio, Poisson's ratio are calculated for ScTiZrHf HE alloy at room temperature using Equation (9) and shown in Table 2.

It is found that the value of Bulk modulus, Young's modulus and Shear modulus of high entropy alloy is smaller than those of other hexagonal alloys [38] (Table 2). Thus, ScTiZrHf high entropy alloy little Stiffness and bonding correspond to other alloys. Pugh's ratio (B/G) and Poisson ratio $(\sigma)$ are measure of in nature with $\sigma=0.23$ and Pugh's ratio $=1.52$; if not it is ductile in nature [30, 32]. Ours finding of lower values of Pugh's ratio and Poisson ratio compared to their critical values indicates that ScTizrHf is brittle in nature at room temperature. It is well known that for stable and elastic material, the value of $\sigma$ should be less than 0.5 . The values of $\sigma$ evaluated for ScTiZrHf are much smaller than the critical value. It indicates that the ScTiZrHf high entropy alloy is stable against shear. A knowledge of these elastic moduli helps in describing all mechanical behaviour of the material. The hardness, compressibility, brittleness, ductileness, toughness and bonding nature of the material are also well associated with second order elastic constants.

\subsection{Ultrasonic Velocity and Ultrasonic allied parameters}

In the present work, we have correlate mechanical and isotropic behaviour of the material with the ultrasonic velocity. We have calculated the longitudinal ultrasonic velocity, shear ultrasonic velocity, Debye average velocity and the thermal relaxation time for ScTiZrHf high entropy alloy. The data for the temperature dependent density $(\rho)$ and the thermal conductivity $(\mathrm{k})$ were taken from the literature [36]. The values of $\mathrm{C}_{\mathrm{V}}$ and $\mathrm{E}_{0}$ have been calculated using the tables of physical constant and Debye temperature. Values of temperature dependent densities, specific heat per unit volume, thermal energy density, thermal conductivity $(\mathrm{k})$ and calculated acoustic coupling constants are shown in Table 3.

From Table 3, it is clear that for all temperatures the values of $\mathrm{D}_{\mathrm{L}}$ are larger than those of $\mathrm{D}_{\mathrm{S}}$. It indicates that for the shear ultrasonic wave the conversion of ultrasonic energy into thermal energy is less than for the longitudinal ultrasonic wave.

The angular dependences of ultrasonic wave velocity $\left(\mathrm{V}_{\mathrm{L}}, \mathrm{V}_{\mathrm{S} 1}, \mathrm{~V}_{\mathrm{S} 2}\right.$, and $\left.\mathrm{V}_{\mathrm{D}}\right)$ at different temperature along $\mathrm{z}-$ axis of the crystal are presented in Figs 1-4. Form Figs. 1 and 2 , indicate that the velocity $\mathrm{V}_{\mathrm{L}}$ has minima and $\mathrm{V}_{\mathrm{S} 1}$ has maxima at $35^{\circ}$ and $45^{\circ}$ respectively with $-\mathrm{z}$ axis of the crystal while form Fig. 3, we find that $\mathrm{V}_{\mathrm{S} 2}$ increases with angle form the z-axis. The abnormal characteristic of angle dependent velocity is due to the collective effect of SOECs and densities. The nature of the angle dependent velocity curves in this work is similar to other hexagonal structured single-phase material. Hence, the angle dependence of the velocities in HEAs is justified.

Fig. 4 shows the variation of the Debye average velocity $\left(V_{D}\right)$ with the angle made with the unique axis of the crystal. It is clear that $V_{D}$ increases with the angle and reaches maximum at $55^{\circ}$. The calculation of $\mathrm{V}_{\mathrm{D}}$ involves the velocities $V_{L}, V_{S 1}$ and $V_{S 2}[40,41]$. It is understandable that the difference of $V_{D}$ is affected by the constituent ultrasonic velocities. The peak in the $\mathrm{V}_{\mathrm{D}}$ verses the angle curve at $55^{\circ}$ is due to a significant increase in longitudinal wave and quasi-shear $\left(\mathrm{V}_{\mathrm{S} 2}\right)$ wave velocities and a decrease in pure shear $\left(\mathrm{V}_{\mathrm{S} 1}\right)$ wave velocity. It may be determined that the average sound wave velocity is maximum when a sound wave travels at $55^{\circ}$ angles with the $\mathrm{z}$ - axis (unique axis) of this crystal. 
Sachin Rai, Navin Chaurasiya, Pramod K. Yadawa

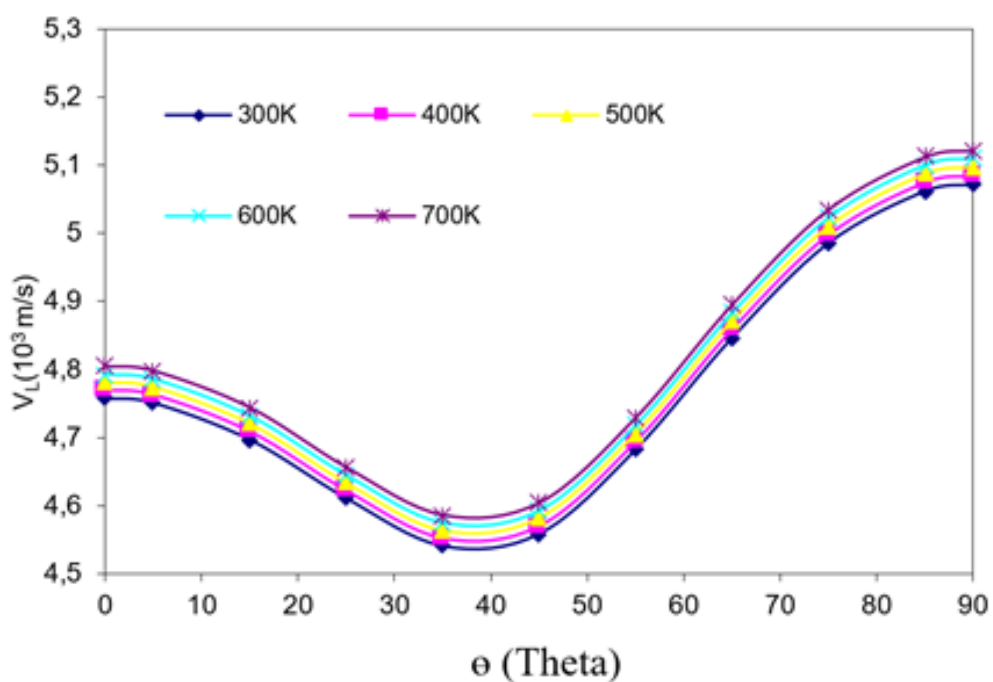

Fig. 1. $V_{L}$ vs Theta with unique axis of crystal.

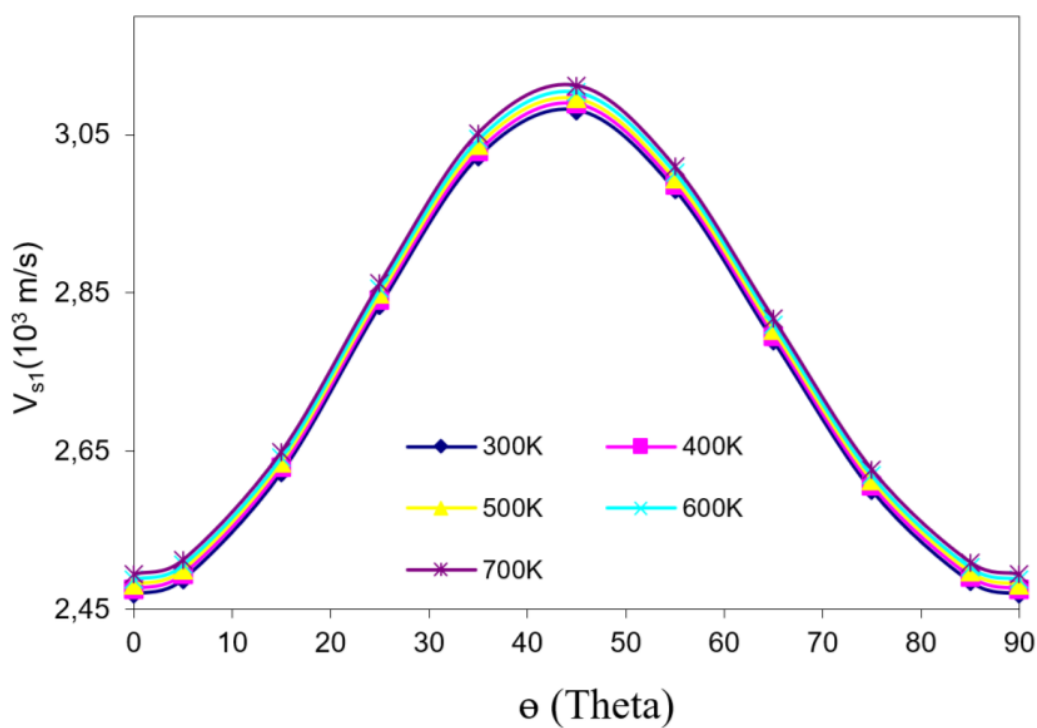

Fig. 2. $V_{\mathrm{S} 1}$ vs Theta with unique axis of crystal.

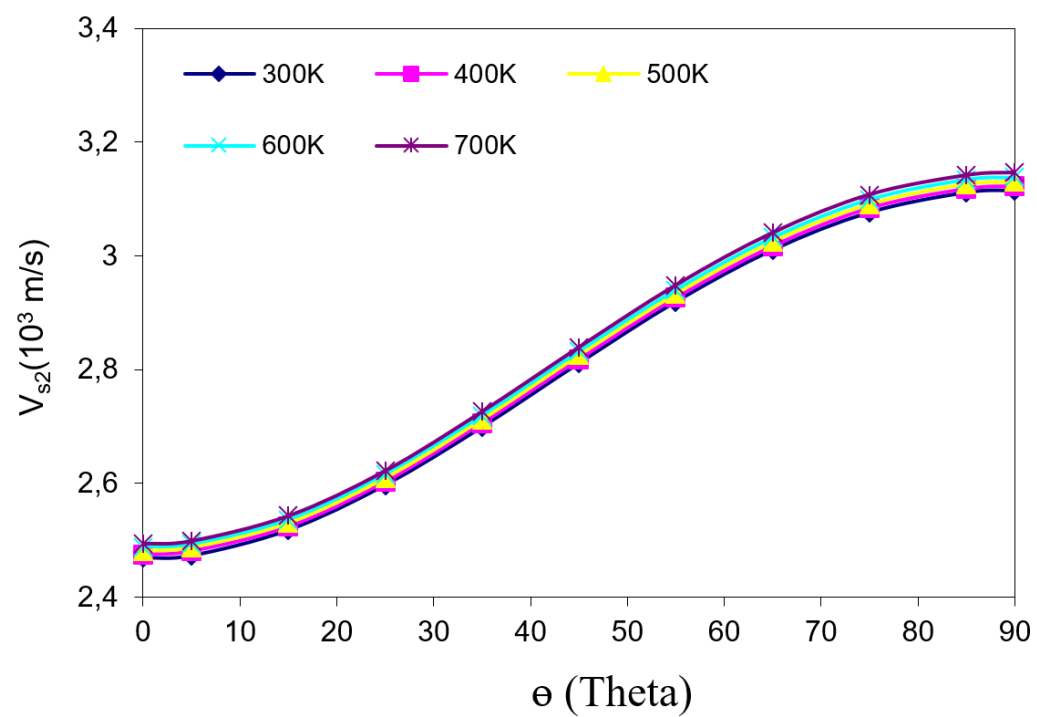

Fig. 3. $\mathrm{V}_{\mathrm{S} 2}$ vs Theta with unique axis of crystal. 


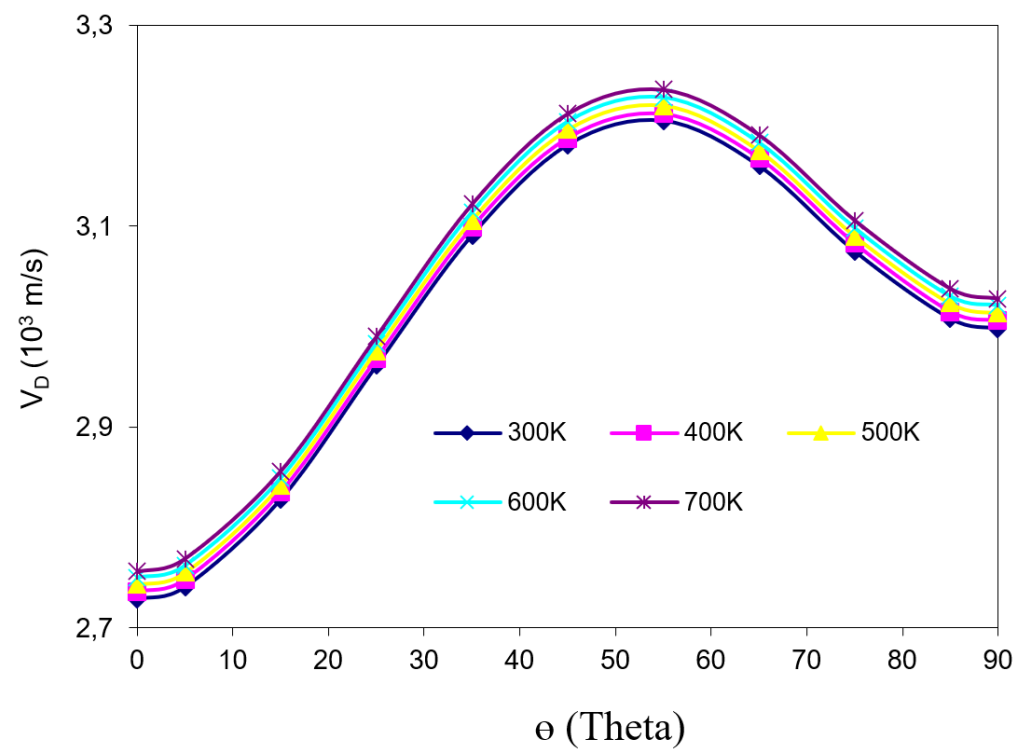

Fig. 4. $V_{D}$ vs Theta with unique axis of crystal.

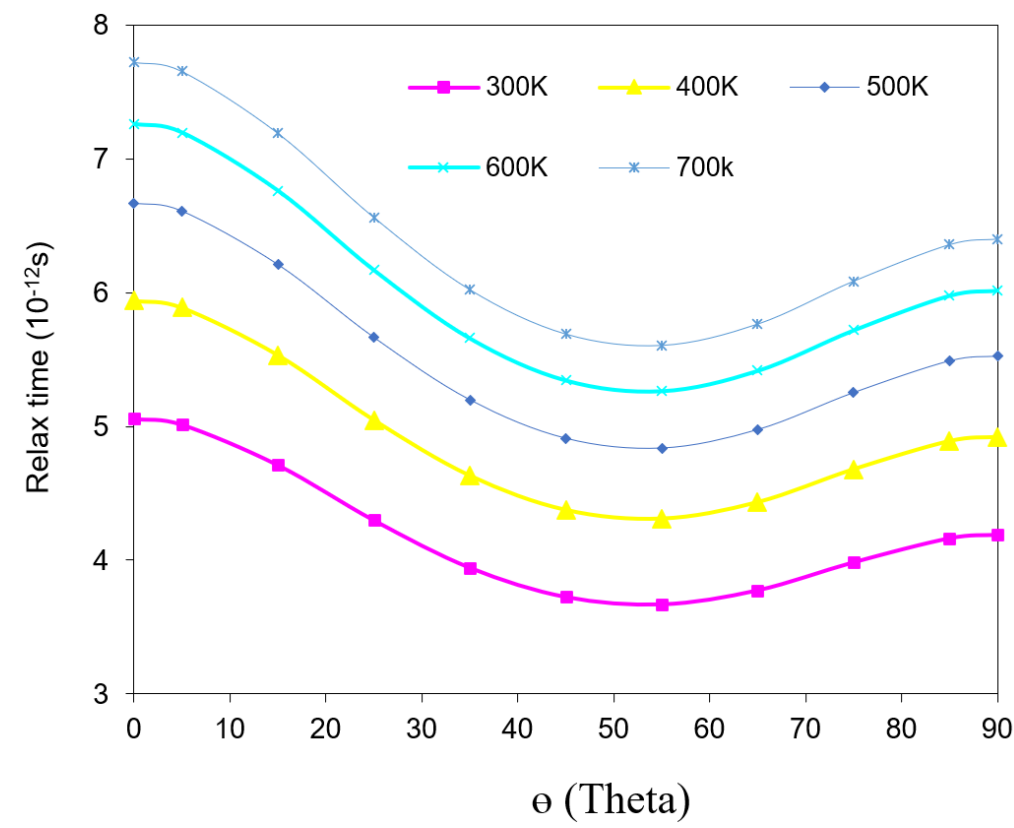

Fig. 5. Relaxation time vs Theta with unique axis of crystal.

Fig. 5 shows a plot of the calculated thermal relaxation time ' $\tau$ ' with the angle (with unique axis of crystal). Angle dependent the thermal relaxation time curves track the reciprocal nature of $\mathrm{V}_{\mathrm{D}}$ as $\tau \propto 3 \mathrm{~K} / \mathrm{C}_{\mathrm{V}} \mathrm{V}_{\mathrm{D}}^{2}$. It is clear that thermal relaxation time of HEAs is mostly affected by the thermal conductivity. For hexagonal structured material $\tau$ is of the order at picoseconds [42, 43]. Hence the calculated ' $\tau$ ' justifies the hexagonal structure of high entropy alloys. The minimum ' $\tau$ ' for wave propagation along $\theta=55^{\circ}$ imply that the reestablishment time for the equilibrium distribution of thermal phonons will be minimum for propagation of wave along this direction.

\subsection{Ultrasonic attenuation due to $p$-p interaction and thermal relaxation phenomena}

While evaluating the UA, it is understood that the wave is propagating along the $\mathrm{z}$-axis $[<001>$ direction] of ScTiZrHf high entropy alloy. The UA coefficient divided by frequency squared $\left(\mathrm{A} / \mathrm{f}^{2}\right)_{\mathrm{Akh}}$ is calculated for longitudinal wave $\left(\mathrm{A} / \mathrm{f}^{2}\right)_{\mathrm{L}}$ and for shear wave $\left(\mathrm{A} / \mathrm{f}^{2}\right)_{\mathrm{S}}$ using Eq.(16) under the condition $\omega \tau \ll 1$ at different temperature. Eq. (19) has been used to calculate the thermo-elastic loss divided by frequency squared $\left(\mathrm{A} / \mathrm{f}^{2}\right)_{\mathrm{Th}}$. Figs. 6-7 present the values of the temperature dependent $\left(\mathrm{A} / \mathrm{f}^{2}\right)_{\mathrm{L}},\left(\mathrm{A} / \mathrm{f}^{2}\right)_{\mathrm{S}},\left(\mathrm{A} / \mathrm{f}^{2}\right)_{\text {Th }}$ and total attenuation $\left(\mathrm{A} / \mathrm{f}^{2}\right)_{\text {total }}$.

It is obvious from Figs. 6 and 7, the Akh. type of energy losses for longitudinal wave, shear waves and the thermo-elastic loss increase with the temperature of material $\left(\mathrm{A} / \mathrm{f}^{2}\right)_{\mathrm{Akh}}$ is proportional to $\mathrm{D}, \mathrm{E}_{0}, \tau$ and $\mathrm{V}^{-3}$ (Eqns. $17,18)$. Table. 3 shows that $\mathrm{E}_{0}$ and $\mathrm{V}$ are increasing with temperature, hence Akhieser losses in ScTiZrHf high entropy alloy is mostly affected by thermal conductivity and thermal energy density. Therefore, the ultrasonic 


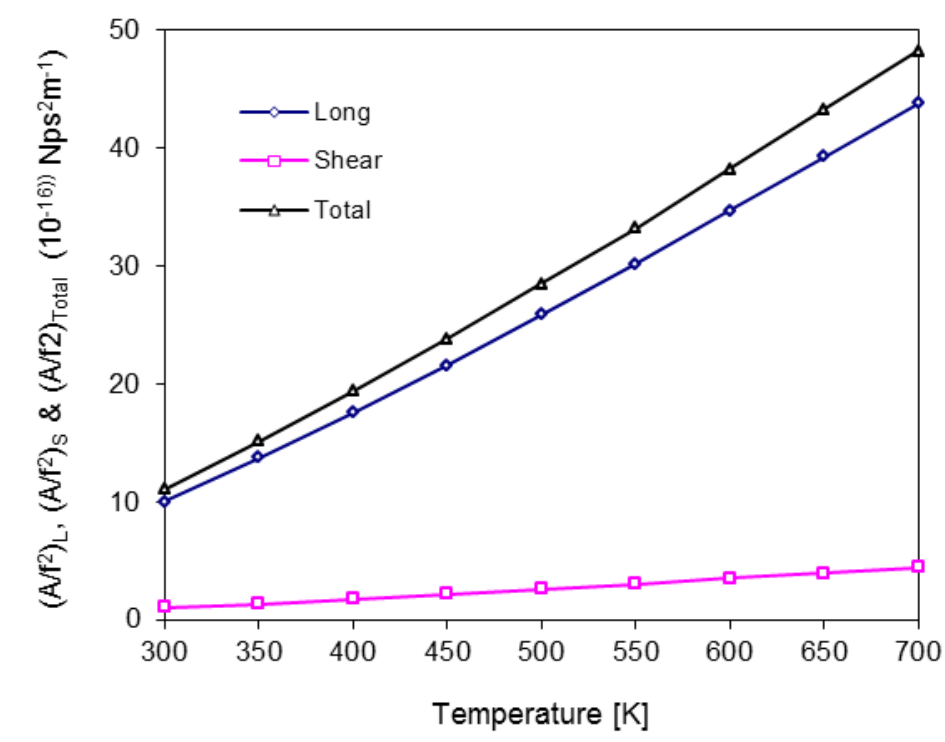

Fig. 6. Long.\& Shear attenuation vs temperature of ScTiZrHf high entropy alloy.

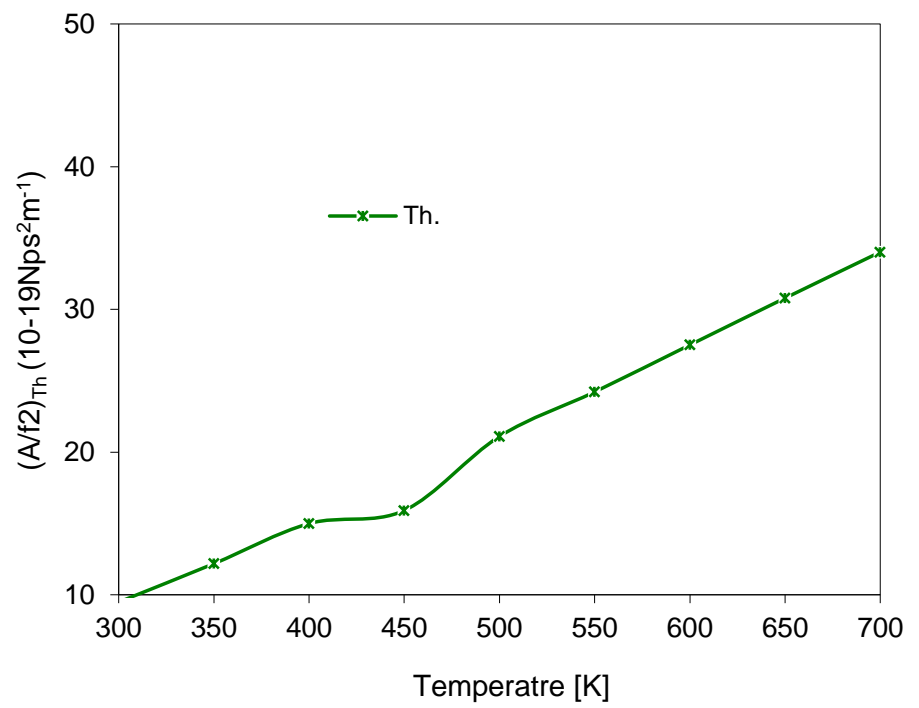

Fig. 7. Th. attenuation vs temperature of ScTiZrHf high entropy alloy.

attenuation increases due to the reduction in the thermal conductivity. Thus, ultrasonic attenuation is mainly governed by the phonon-phonon interaction mechanism. A comparison of the UA could not be made due to lack of experimental data in the literature.

Form Figures 6-7, it is clear that the thermo-elastic loss is very small in comparison to Akhieser loss and also the UA for the longitudinal wave $\left(\mathrm{A} / \mathrm{f}^{2}\right)_{\mathrm{L}}$ is superior than that for the shear wave $\left(\mathrm{A} / \mathrm{f}^{2}\right)_{S}$ of the total attenuation $\left.\left(\mathrm{A} / \mathrm{f}^{2}\right)_{\text {Total }}=\left(\mathrm{A} / \mathrm{f}^{2}\right)_{\mathrm{Th}}+\left(\mathrm{A} / \mathrm{f}^{2}\right)_{\mathrm{L}}+\left(\mathrm{A} / \mathrm{f}^{2}\right)_{\mathrm{S}}\right)$. UA due to $\mathrm{p}-\mathrm{p}$ interaction for longitudinal wave is leading factor. Thermal conductivity and thermal energy density are the main factor that affects the total attenuation. Thus, it may be predicted that ScTiZrHf behave as it's the purest form at room temperature and are more ductile demonstrated by the minimum ultrasonic attenuation while at high temperature (700K) ScTiZrHf high entropy alloy is least ductile. Therefore, at room temperature there will be least impurity in ScTiZrHf high entropy alloy. The minimum
UA for ScTiZrHf at $300 \mathrm{~K}$ defends its quite even hexagonal structure state. This suggests that the interaction between acoustical phonon and quanta of lattice vibration for ScTiZrHf is large in evaluation to other hexagonal materials.

\section{Conclusions}

Based on the exceedingconversation it isuseful to state that:

- The principle established on simple interaction potential model remains valid for calculating higher-order elastic coefficients for hexagonally structured high entropy alloys.

- It has been found that the ScTiZrHf high entropy alloy is mechanically stable.

- For ScTiZrHf high entropy alloy, the thermal relaxation time is found to be of the order of picoseconds, 
which defends their hexagonal structure. As ' $\tau$ ' has smallest value along $\theta=55^{\circ}$, the time for re-establishment of equilibrium distribution of phonons, will be minimum, for the wave propagation in this direction.

- Compared to other hexagonal high entropy alloy, acoustic coupling constants of ScTiZrHf, for the longitudinal wave, are larger. Therefore change of acoustic energy into thermal energy will be larger, for the ScTiZrHf high entropy alloy.

- The ultrasonic attenuation due to phonon-phonon interaction mechanism is predominant over total attenuation as a governing factor thermal conductivity and thermal energy density.

- The mechanical properties of the high entropy alloy ScTiZrHf are superior at room temperature than at high temperatures, since at room temperature the ultrasonic velocity is large and ultrasonic attenuation is small.
- Study can be beneficial for the processing and nondestructive characterization of high entropy alloy. These results will provide a ground for investigating the major thermophysical properties in the field of other HE alloys.

\section{Acknowledgments}

One of us (Sachin Rai) is thankful to Council for Scientific and Industrial Research - University Grant Comission (CSIR - UGC) for providing financial assistance in form of CSIR - Junior Research Fellowship (1500/CSIR-UGC NET dec, 2017) India.

Sachin Rai - Ph. D. Research Scholar;

Navin Chaurasiya - Ph. D. Research Scholar;

Pramod K. Yadawa - Associate Professor

[1] J.W. Yeh, S.K. Chen, S.J. Lin, J.Y. Gan, T.S. Chin, T.T. Shun, C.H. Tsau, S.Y. Chang, Adv. Eng. Mater. 6(5), 299 (2004); https://doi.org/10.1002/adem.200300567.

[2] B. CantorI, T.H. Chang, P. Knight, A.J.B. Vincent, Mater. Sci. Eng. 375-377, 213 (2004) https://doi.org/10.1016/j.msea.2003.10.257.

[3] S.G. Ma, Y. Zhang, Prog. Mater. Sci. 61, 1 (2014); https://doi.org/10.1016/j.pmatsci.2013.10.001.

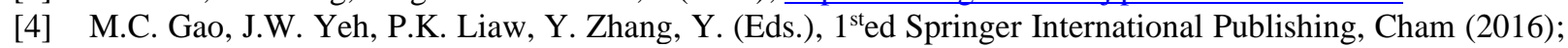
https://www.springer.com/gp/book/9783319270111.

[5] Y. Lu, Y. Dong, S. Guo, L. Jiang, H. Kang, T. Wang, B. Wen, Z. Wang, J. Jie, Z. Cao, H. Ruan, T. Li, Eutectic high- entropy alloys, Sci. Rep. 4, 1 (2014); https://doi.org/10.1038/srep06200.

[6] Y. Lu, X. Gao, L. Jiang, Z. Chen, T. Wang, J. Jie, H. Kang, Y. Zhang, S. Guo, H. Ruan, Y. Zhao, Z. Cao, T. Li, Acta. Mater 124, 143. (2017); https://doi.org/10.1016/j.actamat.2016.11.016.

[7] O.N. Senkov, J.M. Scott, S.V. Senkova, F. Meisenkothen, D.B. Miracle, C.F. Woodward, J. Mater. Sci. 47(9), 4062 (2012); https://doi.org/10.1007/s10853-012-6260-2.

[8] M.C. Gao, B. Zhang, S.M. Guo, J.W. Qiao, J.A. Hawk, Metall. Mater. Trans. A 47A, 3322 (2016); https://doi.org/10.1007/s11661-015-3091-1.

[9] M. Feuerbacher, M. Heidelmann, C. Thomas, Mater. Res. Lett. 3, 1 (2015); https://doi.org/10.1080/21663831.2014.951493.

[10] A. Takeuchi, K. Amiya, T. Wada, K. Yubuta, W. Zhang, JOM 66(10), 1984 (2014); https://doi.org/10.1007/s11837-014-1085-X.

[11] S. Guo, C.T. Liu, Prog.Nat.Sci.Mater Int. 21, 433 (2011); https://doi.org/10.1016/S1002-0071(12)60080-X.

[12] Y. Zhang, T.T. Zuo, Y.Q. Cheng, P.K. Liaw, Sci Rep. 3, 1455 (2013); https://doi.org/10.1038/srep01455.

[13] Y.J. Zhou, Y. Zhang, Y.L. Wang, G.L. Chen, Appl. Phys. Lett. 90, 181904 (2007); https://doi.org/10.1063/1.2734517.

[14] S. Liu, M.C. Gao, P.K. Liaw, Y. Zhang, J. Alloys Compd. 619, 610 (2015); https://doi.org/10.1016/i.jallcom.2014.09.073.

[15] M.H. Chuang, M.H. Tsai, W.R. Wang, S.J. Lin, J.W. Yeh, Acta Mater. 59, 6308 (2011); https://doi.org/10.1016/j.actamat.2011.06.041.

[16] M.C. Gao, J.W. Yeh, P.K. Liaw, Y. Zhang, Switzerland (Springer International Publishing, 2016).

[17] Y.L. Chen, C.W. Tsai, C.C. Juan, M.H. Chuang, J.W. Yeh, T.S. Chin, S.K. Chen, J Alloys Compd. 506, 210 (2010); https://doi.org/10.1016/j.jallcom.2010.06.179.

[18] M. Krnel, S. Vrtnik, A. Jelen, P. Kozelj, Z. Jaglicic, A. Meden, M. Feuerbacher, J. Dolinsek, Intermetallics 117, 106680 (2020); https://doi.org/10.1016/j.intermet.2019.10668.

[19] Q. Lin, J. Liu, X. An, H. Wang, Y. Zhang, X. Liao, Mater. Res. Lett. 6(4), 236 (2018); https://doi.org/10.1080/21663831.2018.1434250.

[20] Y. Zhao, J. Qiao, S. Ma, M. Gao, H. Yang, M. Chen, Y. Zhang. Mater. Des. 96, 10 (2016); https://doi.org/10.1016/j.matdes.2016.01.149.

[21] J.W. Qiao, M.L. Bao, Y. Zhao, H.J. Yang, Y.C. Wu, Y. Zhang, J.A. Hawk, M.C. Gao, J. Appl. Phys. 124(19), 195101 (2018); https://doi.org/10.1063/1.5051514.

[22] E. Mirmahdi, Russian Journal of Nondestructive Testing, 56, 853 (2020); https://doi.org/10.1134/S1061830920100058.

[23] P.K. Yadawa, Pramana-J. Phys.76(4), 613 (2011); https://doi.org/10.1007/s12043-011-0066-7. 
[24] A.I. Potapov, A.V. Kondrat'ev, Ya.G. Smorodinskii, Russian Journal of Nondestructive Testing 55, 434 (2019); https://doi.org/10.1134/S106183091906007X.

[25] A.K. Jaiswal, P.K. Yadawa, R.R. Yadav, $\quad$ Ultrasonics $\quad 89, \quad 22 \quad$ (2018); https://doi.org/10.1016/j.ultras.2018.04.009.

[26] D.K. Pandey, P.K. Yadawa, R.R. Yadav, Mater. Lett. 61, 5194 (2007); https://doi.org/10.1016/j.matlet.2007.04.028.

[27] W. Voigt, Lehrbuch der kristallphysik (mitausschluss der kristalloptik) (Leipzig Berlin, B.G. Teubner, 1928).

[28] A. Reuss. ZAMM-Journal of Applied Mathematics and Mechanics/ZeitschriftfürAngewandteMathematik und Mechanik 9, 49 (1929); http://dx.doi.org/10.1002/zamm.19290090104.

[29] R. Hill. Proc. Phys. Soc, A. 65, 349 (1952); https://doi.org/10.1088/0370-1298/65/5/307.

[30] N. Turkdal, E. Deligoz, H. Ozisik, H.B. Ozisik, Ph. Transit. 90, 598 (2017); https://doi.org/10.1080/01411594.2016.1252979.

[31] F. Philippe, E.W. Weck, T. Veena, A. John, Dalton Trans. 44, 18769 (2015); https://doi.org/10.1039/c5dt03403e.

[32] N. Yadav, S.P. Singh, A. K. Maddheshiya, P.K. Yadawa and R.R Yadav, Phase Transitions 93, 883 (2020); https://doi.org/10.1080/01411594.2020.1813290.

[33] D. Singh, D.K. Pandey, P.K. Yadawa, A.K. Yadav, $\quad$ Cryogen. $49, \quad 12 \quad$ (2009); https://doi.org/10.1016/j.cryogenics.2008.08.008.

[34] D. Singh, $\quad$ P.K. $\quad$ Yadawa, S.K. Sahu, $\quad$ Cryogen. $\quad 50, \quad 476 \quad$ (2010); https://doi.org/10.1016/j.cryogenics.2010.04.005.

[35] S. Uporov, S.K. Estemirova, V.A. Bykov, D.A. Zamyatin, R.E. Ryltsev, Intermetallics 122, 106802 (2020); https://doi.org/10.1016/j.intermet.2020.106802.

[36] K.V. Petrov, O.V. Murav'eva, Yu.V. Myshkin, A.F. Basharova, Russian Journal of NondestructiveTesting, 55, 102 (2019); https://doi.org/10.1134/S1061830919020062.

[37] R.I. Romanishin, I.M. Romanishin, M.M. Student, V.M. Gvozdetskii, B.P. Rusin, G.I. Romanishin, V.V. Koshevoi, S.I. Semak, R.E. Krygul, Russian Journal of Nondestructive Testing, 54, 479 (2018); https://doi.org/10.1134/S1061830918070069.

[38] P.K. Yadawa, The Arabian Journal for Science and Engineering 37, 255 (2012); https://doi.org/10.1007/s13369-011-0153-6.

[39] P.K. Yadawa, Adv. Mat. Lett, 2(2), 157 (2011); https://doi.org/10.5185/amlett.2010.12190.

[40] C.P. Yadav, D.K. Pandey and D. Singh, Indian J. Phys. 93, 1147 (2019); https://doi.org/10.1007/s12648-01901389-8.

[41] D.K. Pandey, P.K. Yadawa and R.R. Yadav, Mat. Lett. 61, 4747 (2007); https://doi.org/10.1016/j.matlet.2007.03.031.

[42] S.P. Singh, G. Singh, A.K. Verma, P.K. Yadawa, R.R. Yadav, Pramana-J. Phys. 93, 83 (2019); https://doi.org/10.1007/s12043-019-1846-8.

[43] P.K. Yadawa, Ceramics-Silikaty 55, 127 (2011); https://www.ceramics-silikaty.cz/2011/2011_02_127.htm.

\title{
С. Рai, Н. Чауразія, П.К. Ядава \\ Пружні, механічні та теплофізичні властивості однофазного четвертинного високоентропійного сплаву ScTiZrHf
}

\author{
Кафедра фізики, Інститут фізичних наук професора Раджендра Сінгха (RajјиBhaiya), \\ В Б.С. Університет Пурванчал, Джаунпур, Індія, pkyadawa@gmail.com
}

\begin{abstract}
Відповідно до моделі потенціалу взаємодії, розраховано константи пружності високого порядку для високоентропійних сплавів в однофазному четвертинному сплаві ScTiZrHf при кімнатній температурі. Пружні константи другого порядку (SOECs) допомагають визначити інші ультразвукові параметри. За допомогою SOECs інші модулі пружності (модуль об'ємної пружності, модуль зсуву, модуль Юнга, коефіцієнт П’ю, константи пружної жорсткості та коефіцієнт Пуассона) оцінюються при кімнатній температурі для пружності та механічних характеристик. Інші ультразвукові параметри розраховуються при кімнатній температурі для пружної та механічної характеристики. За допомогою SOEC оцінено зміну температури ультразвукових швидкостей уздовж осі z кристала. Уздовж цієї осі орієнтації також оцінено температурні зміни середньої швидкості Дебая та часу теплової релаксації $(\tau)$. Також проаналізовано ультразвукові властивості, пов'язані із пружними, тепловими та механічними властивостями, які залежать від температури. Розраховано загасання ультразвуку внаслідок фонон-фононної (р-p) взаємодії при різних температурах. При дослідженні ультразвукового ослаблення, як функції температури, показано, що теплопровідність є основним фактором, а р-р-взаємодія відповідає за ослаблення, і виявлено, що механічні властивості високоентропійного сплаву ScTiZrHf кращі при кімнатній температурі.

Ключові слова: високоентропійний сплав, ультразвукові властивості, теплопровідність, пружні властивості.
\end{abstract}

